\title{
PENTINGNYA PENGUMPULAN DATA DALAM PROSES \\ KEPERAWATAN UNTUK MEMPEROLEH HASIL ASUHAN \\ KEPERAWATAN YANG BERMUTU
}

\author{
Inayah Husna Sibarani / inayahhusna08@gmail.com
}

\section{LATAR BELAKANG}

Asuhan keperawatan adalah suatu pendekatan untuk pemecahan masalah pada pasien dengan memberikan pelayanan keperawatan. Sejauh ini perawat tidak sepenuhnya melakukan asuhan keperawatan sesuai dengan SOP. Asuhan keperawatan adalah suatu pendekatan untuk pemecahan masalah yang memampukan perawat untuk mengatur dan memberikan asuhan keperawatan. Standar asuhan yang tercantum dalam Standar Praktik Klinis Keperawatan terdiri dari lima fase asuhan keperawatan: 1) Pengkajian; 2) Diagnosa; 3) Perencanaan; 4) Implementasi; dan 5) Evaluasi. Salah satu manfaat dari penerapan asuhan keperawatan yang baik adalah meningkatkan mutu dan kualitas pelayanan dalam bidang keperawatan (Kozier, 2010).

Rumah sakit merupakan sebuah organisasi kesehatan yang sangat bermanfaat guna memberikan pelayanan kesehatan bagi masyarakat, sebagaimana tertera dalam UU RI No 44 pasal 1 (2009, p.2). Setiap tenaga kesehatan yang bekerja dirumah sakit harus bekerja sesuai dengan standar profesi, standar pelayanan rumah sakit, standar prosedur operasional yang berlaku, etika profesi, menghormati hak pasien, dan mengutamakan keselamatan pasien. Tenaga kesehatan tersebut diantaranya tenaga medis dan penunjang medis, tenaga keperawatan, tenaga kefarmasian, tenaga manajemen rumah sakit dan tenaga non kesehatan UU RI No 44 pasal 12-13 (2009, p.11-12). Salah satu pelayanan kesehatan yang diberikan oleh tenaga kesehatan adalah pelayanan keperawatan, Sebagai bagian dari pelayanan kesehatan, maka pelayanan keperawatan yang dilakukan oleh tenaga perawatmemiliki tugas diataranya memberikan asuhan keperawatan (Hidayat, 2011, p.75).

Para praktisi keperawatan tentu telah paham cara merumuskan diagnosa keperawatan sebagai langkah kedua dari proses keperawatan. Pemberian asuhan keperawatan pada saat ini masih lebih banyak terfokus pada upaya penyembuhan penyakit atau respons klien terhadap 
penyakit. Hal ini berdampak pada diagnosa yang ditetapkan oleh perawat umumnya berkaitan dengan masalah klien yang bersifat actual dan risiko saja atau diagnosa keperawatan aktual dan risiko saja.

\section{METODE}

Kajian ini menggunakan metode kualitatif, metode ini bersifat memberikan penjelasan dengan membuat analisis. Proses pengkajian ini lebih menggunakan landasan teori dengan mengumpulkan data, bereksplorasi bebas yang telah disimpulkan dari berbagai sumber-sumber, yaitu buku, majalah, koran, jurnal print maupun jurnal online bertema perencanaan keperawatan. Saya membaca dari berbagai referensi berupa buku, jurnal print maupun jurnal online. Melalui metode ini saya mengetahui dan memahami proses keperawatan untuk memperoleh asuhan keperawatan yang bermutu terhadap perawat yang sedang bertugas. Sehingga mengetahui pengantar proses keperawatan.

\section{HASIL}

Berdasarkan hasil yang saya dapatkan, dokumentasi merupakan bagian dari pengkajian. Standar asuhan yang tercantum dalam Standar Praktik Klinis Keperawatan terdiri dari lima fase asuhan keperawatan: 1) Pengkajian; 2) Diagnosa; 3) Perencanaan; 4) Implementasi; dan 5) Evaluasi.

Proses keperawatan adalah serangkaian tindakan yang sistematis berkesinambungan meliputi tindakan untuk mengidentifikasi masalah kesehatan individu atau kelompok baik yang aktual maupun potensial kemudian merencanakan tindakan untuk menyelesaikan, mengurangi, atau mencegah terjadinya masalah baru dan melaksanakan tindakan atau menugaskan orang lain untuk melaksanakan tindakan keperawatan serta mengevaluasi keberhasilan dari tindakan yang dikerjakan (Rohmah, $\mathrm{N}$ dan Walid, S. 2009).

Pengetahuan yang kurang pada perawat sangat berhubungan dengan pendokumentasian yang kurang. Karena itu direkomendasikan supaya pendokumentasian dapat dilakukan dengan baik, maka diperlukan sikap positif.

Kualitas asuhan yang berfokus pada tampilan kinerja keperawatan melalui proses keperawatan merupakan sebuah indikator yang penting dan dapat diukur dari dokumentasi keperawatan (Xiao et al., 2017).

Pelayanan keperawatan akan lebih memuaskan tentunya dengan penerapan model asuhan keperawatan professional atau MAKP karena kepuasan pasien ditentukan salah satunya dengan pelayanan keperawatan yang optimal (Fisbach, 1991 dalam jurnal Nur Hidayah, 2014).

Sistem model asuhan keperawatan professional (MAKP) adalah suatu 
kerangka kerja yang mendefinisikan empat unsur yakni standar, proses keperawatan, pendidikan keperawatan, sistem MAKP. Perawat profesional dalam memberikan pelayanan keperawatan di masa depan adalah harus dapat berkomunikasi secara lengkap, adekuat dan cepat (Nursalam, 2012).

Untuk menilai kualitas pelayanan keperawatan diperlukan adanya standar praktik keperawatan yang merupakan pedoman bagi perawat dalam melaksanakan asuhan keperawatan yang diwujudkan dalam bentuk proses keperawatan baik dari pengkajian sampai evaluasi (Nursalam, 2008).

\section{PEMBAHASAN}

Rumah Sakit merupakan tempat rujukan medis dan kesehatan serta merupakan institusi yang padat ilmu, padat modal, padat karya dan padat teknologi, tempat berbagai profesi bekerja sama, seyogyanya menjadi pusat informasi bagi pasien dan masyarakat pada umumnya, sekaligus bagi pusat kesehatan sendiri (Departemen Kesehatan RI, 1997).

Keperawatan merupakan suatu bentuk pelayanan profesional bersifat humanistik, menggunakan pendekatan holistik, dilakukan berdasarkan ilmu dan kiat keperawatan, berorientasi kepada kebutuhan objektif klien. Praktek keperawatan mengacu pada standar professional keperawatan dan menggunakan etika keperawatan sebagai tuntutan utama. Perawat dituntut untuk selalu melaksanakan asuhan keperawatan yang benar atau rasional (Nursalam, 2007). Proses asuhan keperawatan merupakan tugas dan kewajiban seorang perawat dari pasien datang sampai pasien pulang, dimulai dengan pengkajian secara menyeluruh, kemudian menegakkan diagnosa keperawatan dari data pengkajian tersebut, serta melaksanakan intervensi, implementasi dan evaluasi keefektifan diagnosa awal yang sudah ditegakkan (Nursalam, 2007). Asuhan profesional dituntut untuk dapat melaksanakan proses keperawatan dengan tepat dan benar. Pemahaman mahasiswa terhadap proses perawatan sangat penting, karena topik ini akan menjadi bagian yang amat penting dalam pelaksanaan asuhan keperawatan. Perbedaan asuhan yang profesional dengan asuhan tradisional terletak pada penggunaan proses keperawatan. Kemampuan perawat dalam menerapkan proses keperawatan dalam asuhannya sudah tidak dapat ditawar lagi apabila ia meyakini bahwa asuhannya adalah asuhan yang profesional (Rohmah, N dan Walid, S. 2009).

Proses keperawatan merupakan gambaran dari hubungan antara pasien dan perawat, identitas dan peran profesionalitas 
perawat, dan pengembangan pengetahuan perawat. Antusiasme perawat dalam menerima tantangan baru dalam memberikan pelayanan telenursing sangat tinggi, hal tersebut dapat berdampak pada kemampuan meningkatkan komunikasi yang efektif antara perawat dan pasien (Padila et al., 2018). Hubungan antara pasien dan perawat merupakan interaksi timbal balik dimana respon pasien dan perawat saling memengaruhi dan terus berkembang sejalan dengan perubahan respon antara pasien dan perawat. Salah satu fungsi profesionalitas perawat adalah menemukan kebutuhan pasien yang tidak terpenuhi dan kemudian memberikan bantuan untuk memenuhi kebutuhan tersebut. Proses keperawatan memfasilitasi perawat untuk berkembang sebagai seorang pemikir yang logis untuk menghasilkan peningkatan respon dan perilaku pasien dalam pemenuhan kebutuhannya serta pentingnya partisipasi pasien dalam keseluruhan proses (Stonehouse, 2017).

Langkah utama dalam memberikan asuhan keperawatan untuk membantu klien mencapai kesejahteraan adalah melalui pengkajian terhadap kemampuan klien melakukan perawatan diri, pengkajian jaringan dukungan sosial klien, dan pengkajian lingkungan tempat klien tinggal dan berinteraksi. Kemudian intervensi yang memudahkan klien mencapai tujuan diimplementasikan oleh perawat. Intervensi ini difokuskan pada peningkatan kemampuan klien untuk melakukan perawatan diri, membantu klien mengembangkan sistem dukungan sosial, atau memelihara dan mengubah lingkungan untuk mempermudah upaya mencapai kesejahteraan.

Pengkajian merupakan langkah pertama dari proses keperawatan dengan kegiatan pengumpulan data, memvalidasi data pengorganisasian data dan mencatat data yang diperoleh. Langkah ini merupakan dasar untuk perumusan diagnosis keperawatan dan mengembanggkan rencana keperawatan sesuai kebutuhan pasien serta melakukan implementasi keperawatan (Abd Wahid \& Imam Suprapto, 2012) dan (Potter dan Perry, 2005).

Penerapan kompetensi proses keperawatan di lahan klinik juga dapat dinilai dari pencatatan dan pelaporan yang dituliskan dalam bentuk pendokumentasian asuhan keperawatan yang secara keseluruhan setiap tahapannya dikenal dengan tahapan proses keperawatan. Disisi lain pendokumentasian asuhan keperawatan merupakan bukti fisik aktivitas atau kinerja perawat dalam bentuk data administrasi yang mutlak harus ada karena memiliki banyak manfaat. Salah satu manfaat dari pendokumentasian asuhan keperawatan adalah menunjukan profesionalisme perawat di tatanan 
pelayanan klinis. Menurut Potter dan Perry (2005), dokumentasi merupakan segala sesuatu yang tertulis atau tercetak yang dapat diandalkan sebagai catatan tentang bukti individu.

Dokumentasi keperawatan merupakan bukti pencatatan dan pelaporan yang dimiliki perawat dalam melakukan catatan keperawatan yang berguna untuk kepentingan klien, perawat dan tim kesehatan dalam memberikan pelayanan kesehatan dengan dasar komunikasi yang akurat dan baik secara tertulis dengan tanggung jawab perawat (Hidayat, 2007).

Pendokumentasian asuhan keperawatan adalah proses pelaksanaan pencatatan asuhan keperawatan yakni dari pengkajian saat masuk sampai pasien dinyatakan sehat. Diagnosis yang diangkat berdasarkan masalah yang ditemukan, perencanaan keperawatan, tindakan yang dilakukan serta evaluasi dari proses asuhan keperawatan yang diberikan (Nursalam, 2007).

Pengetahuan yang kurang pada perawat berhubungan dengan pendokumentasian yang kurang. Insentif yang kurang berhubungan dengan pendokumentasian kurang. Beban kerja yang tidak sesuai berhubungan dengan pendokumentasian kurang. Karena itu direkomendasikan supaya pendokumentasian dapat dilakukan dengan baik, maka diperlukan sikap positif. Agar sikap perawat positif diperlukan pengetahuan yang baik, insentif yang cukup dan beban kerja yang sesuai. Sehingga disarankan untuk:

1. Insentif bagi perawat yang melakukan pendokumentasian baik belum terealisasi dikarenakan masih terhambat, sehingga disarankan pemberian insentif diberikan secara berkala sesuai dengan penilaian/ rapor perawat dalam pendokumentasian asuhan keperawatan yang dilakukan perawat. Pemberian insentif dapat berupa bonus uang jasa, penghargaan perawat teladan, pengiriman pada seminar, pelatihan bagi perawat yang melakukan pendokumentasian asuhan keperawatan dengan baik

2. Pengetahuan perawat yang baik dalam pendokumentasian masih kurang dikarenakan kurangnya penyegaran dan pembinaan mengenai pendokumetasian itu sendiri, sehingga disarankan agar dilakukan penyegaran rutin keperawatan mengenai pendokumentasian dan melakukan pembinaan melalui In House Training guna peningkatan pengetahuan perawat dalam pendokumentasian asuhan keperawatan.

3. Beban kerja yang sesuai pada tiap ruang rawat masih belum terealisasi, hal ini dikarenakan jumlah tenaga perawat yang ada sangat kurang jika dilihat dari jumlah pasien, sehingga disarankan meningkatkan 
sumber daya perawat guna mengoptimalkan pelaksanaan pendokumentasian asuhan keperawatan yang baik.

Kualitas asuhan yang berfokus pada tampilan kinerja keperawatan melalui proses keperawatan merupakan sebuah indikator yang penting dan dapat diukur dari dokumentasi keperawatan (Xiao et al., 2017). Sejarah fokus dokumentasi keperawatan sebelumnya berorientasi pada dokumentasi proses keperawatan yang komprehensif dan kemudian berkembang menjadi diagnosis keperawatan yang lengkap namun belum memerhatikan kualitas dari dokumentasi diagnosis keperawatan, intervensi, dan luaran.

Pelayanan keperawatan akan lebih memuaskan tentunya dengan penerapan model asuhan keperawatan professional atau MAKP karena kepuasan pasien ditentukan salah satunya dengan pelayanan keperawatan yang optimal (Fisbach, 1991 dalam jurnal Nur Hidayah, 2014). Untuk menilai kualitas pelayanan keperawatan diperlukan adanya standar praktik keperawatan yang merupakan pedoman bagi perawat dalam melaksanakan asuhan keperawatan yang diwujudkan dalam bentuk proses keperawatan baik dari pengkajian sampai evaluasi (Nursalam, 2008).

\section{PENUTUP}

Keperawatan adalah sesuatu yang esensial dan sangat penting yang diberikan oleh perawat terhadap individu, keluarga dan masyarakat yang bertujuan untuk menyelesaikan masalah dan memenuhi kebutuhan pasien. Proses keperawatan adalah: serangkaian tindakan yang secara berurutan dan sistematis melalui pendekatan ilmiah untuk mengatasi dan memecahkan masalah klien, dan memenuhi kebutuhan klien. Pelayanan asuhan keperawatan dilaksanakan melalui lima tahap proses keperawatan: pengkajian, diagnosa, perencanaan, implementasi dan evaluasi.

\section{Dokumentasi}

keperawatan merupakan bukti pencatatan dan pelaporan yang dimiliki perawat dalam melakukan catatan keperawatan yang berguna untuk kepentingan klien, perawat dan tim kesehatan dalam memberikan pelayanan kesehatan dengan dasar komunikasi yang akurat dan baik secara tertulis dengan tanggung jawab perawat (Hidayat, 2007). 


\section{DAFTAR PUSTAKA}

Budiono. (2016). Konsep Dasar Keperawatan. Jakarta: Pusdik SDM Kesehatan.

Budiono. Pertami, S.B. (2016). Konsep Dasar Keperawatan. Jakarta: Bumi Medika.

Bumulo, Muhammad Iqbal. Bidjuni, Hendro. Bawotong, Jeavery. (2017). PENGARUH MANAJEMEN MODEL ASUHAN KEPERAWATAN PROFESIONAL TIM TERHADAP KUALITAS PELAYANAN KEPERAWATAN DI BANGSAL PRIA RSUD DATOE BINANGKANG KABUPATEN BOLAANG MONGONDOW. e-Jurnal Keperawatan (eKp), Volume 5 Nomor 2, 1-6.

Fatie, Marselius. Felle, Zeth Roberth. (2018). HUBUNGAN TINGKAT PENDIDIKAN PERAWAT DENGAN PENERAPAN KOMPETENSI PENDOKUMENTASIAN PROSES KEPERAWATAN. JURNAL KEPERAWATAN TROPIS PAPUA. VOLUME 01 NOMOR 01, $19-24$.

Koerniawan, Dheni. Daeli, Novita Elisabeth. Srimiyati. (2020). APLIKASI STANDAR PROSES KEPERAWATAN: DIAGNOSIS, OUTCOME, DAN INTERVENSI PADA ASUHAN KEPERAWATAN. Jurnal Keperawatan Silampari, Volume 3, Nomor 2, 739-751. Kusandi, Elon. (2017). Analisis Kelengkapan Dokumentasi Keperawatan di Ruang Rawat Inap Non Intensive Rumah Sakit X. Jurnal Bidang Ilmu Kesehatan, Vol. 9, No. 1, 553-562.

Nurjannah, Intansari. Pamungkas, Dewi Retno. Warsini, Sri. (2017). PERBANDINGAN ANTARA DIAGNOSIS YANG SERING DITEGAKKAN DAN POSSIBLE DIAGNOSIS YANG DIPREDIKSIKAN OLEH PERAWAT PADA KLIEN DENGAN GANGGUAN JIWA. Jurnal Keperawatan Klinis dan Komunitas, Vol.01/No.01, 8-15.

Rohmah, Nikmatur. (2010). INTEGRASI PROSES KEPERAWATAN DALAM PEMBELAJARAN KLINIK KEPERAWATAN ONE TO ONE TEACHING AND FEED BACK. THE INDONESIAN JOURNAL OF HEALTH SCIENCE, Vol. 1, No. 1, 51-60.

Rosdahl, B. C. \& Kowalski, T. M. (2014). Buku Ajar Keperawatan Dasar. Ed.10. Vol 1. Jakarta: EGC.

Simamora. R. H. (2008) The correlation of ward chief's giving direction and command and the performance of on-duty nurses at Jember dr. Subandi general hospital inpatient wards. jurnal Administrasi dan Kebijakan Kesehatan, (https://fkm.unair.ac.id/jurnal-administr) 
Wirdah, Husnul \& Yusuf, Muhammad. (2016). Penerapan Asuhan Keperawatan Oleh Perawat Pelaksana di Rumah Sakit Banda Aceh. Banda Aceh: Universitas Syah Kuala.

Wulandini S., Putri. Krianto, Tri. Priwahyuni, Yuyun. (2016). FAKTOR-FAKTOR YANG BERHUBUNGAN DENGAN PENDOKUMENTASIAN ASUHAN KEPERAWATAN DI RUMAH SAKIT JIWA. NERS JURNAL KEPERAWATAN, Volume 12, No.2, 131-142. 